\title{
Análise inicial do uso e ocupação em trecho do riacho Ouro Preto - Olinda/PE - e sua influência para a potencialização de eventos de inundações
}

\author{
Initial analysis of the use and occupation in Ouro Preto creek stretch - Olinda / PE - and its \\ influence for the enhancement of floods events
}

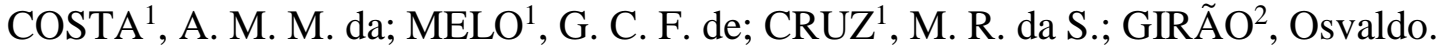 \\ anamouracosta08@gmail.com
}

\begin{abstract}
Resumo
Este trabalho tem o objetivo de mostrar um estudo inicial sobre o uso e a ocupação do solo nas margens do riacho de Ouro Preto, bairro de Ouro Preto em Olinda Pernambuco, que faz parte da Bacia Hidrográfica do Rio Paratibe, sendo um canal fluvial de $1^{\text {a }}$ ordem afluente do rio Fragoso. A área estudada apresenta uma configuração retilínea, com perfil longitudinal e pontos de maior profundidade, desse modo, o bairro sofre eventos de alagamentos decorrentes do período chuvoso. A intensificação de residências nas margens do canal é uma das causas para ocorrências de enchente no bairro, porém, isso tende a acontecer também por ausência de planejamento e gestão, voltadas para o controle dos dos espaços urbanos.
\end{abstract}

Palavras-chaves: Canal fluvial; Enchente; Espaço urbano.

\begin{abstract}
This work aims to show an initial study on the use and occupation of land on the banks of Ouro Preto stream, Ouro Preto neighborhood of Olinda - Pernambuco, which is part of the River Basin Paratibe, with a fluvial channel 1st order tributary of the river Fragoso. The study area has a rectilinear configuration with longitudinal profile and points of greater depth, thereby, the neighborhood suffers flooding events resulting from the rainy season. Intensification of homes on the banks of the canal is one of the causes of flood events in the neighborhood, but it also tends to happen due to lack of planning and management, focused on the control of urban spaces.
\end{abstract}

Keywords: Fluvial channel; Flood; Urban space.

\section{INTRODUÇÃO}

Os alagamentos, transbordamentos e consequentes inundações das margens de um curso d’água é um fenômeno natural da dinâmica fluvial e sua ocorrência permite que exista a conectividade hidrológica longitudinal, lateral e vertical entre os domínios do canal e da planície de inundação e seus compartimentos. A periodicidade da ocorrência de tais fenômenos está associada originalmente ao regime climático ou hidrológico particular de cada bacia hidrográfica.

Para tanto, considera-se que, a ausência de ações de planejamento e gestão voltadas para o controle do uso e ocupação da terra em espaços urbanos responde por consequências danosas à dinâmica hidrogeomorfológica de uma bacia hidrográfica, considerando os domínios fluviais e interfluviais.

No processo de ocupação urbana brasileira, os cursos d’água ainda são poucos considerados ou até mesmo negligenciados no ordenamento ambiental e territorial, o que repercute no incremento do

${ }^{1}$ Ana Márcia M. da Costa Graduanda, DCG-UFPE/Programa de Educação Tutorial - PET Geografia, Recife-PE, Brasil

${ }^{1}$ Gysllaynne C. Farias de Melo, Graduanda, DCG-UFPE/Sensoriamento Remoto e Geoprocessamento - SERGEO, Recife-PE, Brasil.

${ }^{1}$ Maria Rafaela da S. Cruz, Graduanda, DCG-UFPE/Grupo de Estudos do Quaternário do Nordeste Brasileiro-GEQUA, Recife-PE, Brasil.

${ }^{2}$ Osvaldo Girão, Docente, DCG-UFPE/Grupo de Estudos do Quaternário do Nordeste Brasileiro - GEQUA, Recife-PE, Brasil. 
escoamento superficial, originado a partir da expansiva impermeabilização e consequente redução dos índices de infiltração, refletindo no aumento do nível da água acima das margens do canal e o transbordamento do escoamento para a planície aluvial, que em ambientes urbanos encontram-se densamente povoados, fazendo com que os eventos de alagamentos e inundações tornem-se recorrentes e cada vez mais intensos, causando danos materiais e infraestruturais para comunidades que ocupam áreas próximas aos canais.

Nesse estudo, de caráter inicial, buscou-se analisar como as formas de uso e ocupação da terra em um trecho de aproximadamente 760 metros do riacho Ouro Preto, bairro de Ouro Preto em Olinda/PE, influência na potencialização de eventos de inundações na localidade quando de eventos pluviais moderados a fortes.

\section{METODOLOGIA}

O presente trabalho optou por uma abordagem metodológica dialética, atrelada a uma interpretação dinâmica e totalizante da realidade, considerando eventos naturais que não podem ser considerados fora de um contexto sócio-político e econômico. Além de um levantamento bibliográfico teórico-conceitual foi acrescida duas atividades in loco para avaliação do trecho considerado. A primeira visita de campo, foi realizada para o reconhecimento do trecho, com isso definiu-se um percurso de aproximadamente 760 metros, da rua Ouriço do Mar até o seu encontro com a rodovia PE-15. A segunda incursão foi para a coleta dos pontos, definiu-se assim as coordenadas geográficas da nascente (7 59’44.00” S - 34 52’07.89” W) e da foz (7 59’00.16” S - 34 50’41.33” W) que perfaz um curso de 3,5 quilômetros. Utilizou-se o GPS Garmin, modelo Etrex, com erro mínimo de três metros, no Sistema de Coordenadas Geográficas, com datum Córrego Alegre, sistema UTM no fuso 25, em unidades métricas. Ainda foram utilizadas ferramentas de medição na margem e no interior do canal para análise da fluidez da água, e assim criar um perfil longitudinal altimétrico do interior, esse último foi medido em cada 8 metros no decorrer do trecho. Os dados coletados foram avaliados no Sistemas de Informações Geográficas (SIG) e Google Earth. Durante as atividades de campo foram estudadas as formas de usos e ocupações marginais do riacho de Ouro Preto, e como tais usos potencializam processos de alagamentos e inundações do canal fluvial em questão.

\section{RESULTADOS E DISCUSSÕES}

O riacho Ouro Preto faz parte da Bacia Hidrográfica do Rio Paratibe, sendo um canal de $1^{\mathrm{a}}$ ordem afluente do rio Fragoso localizado na porção central do município de Olinda-PE (Figura 1). 


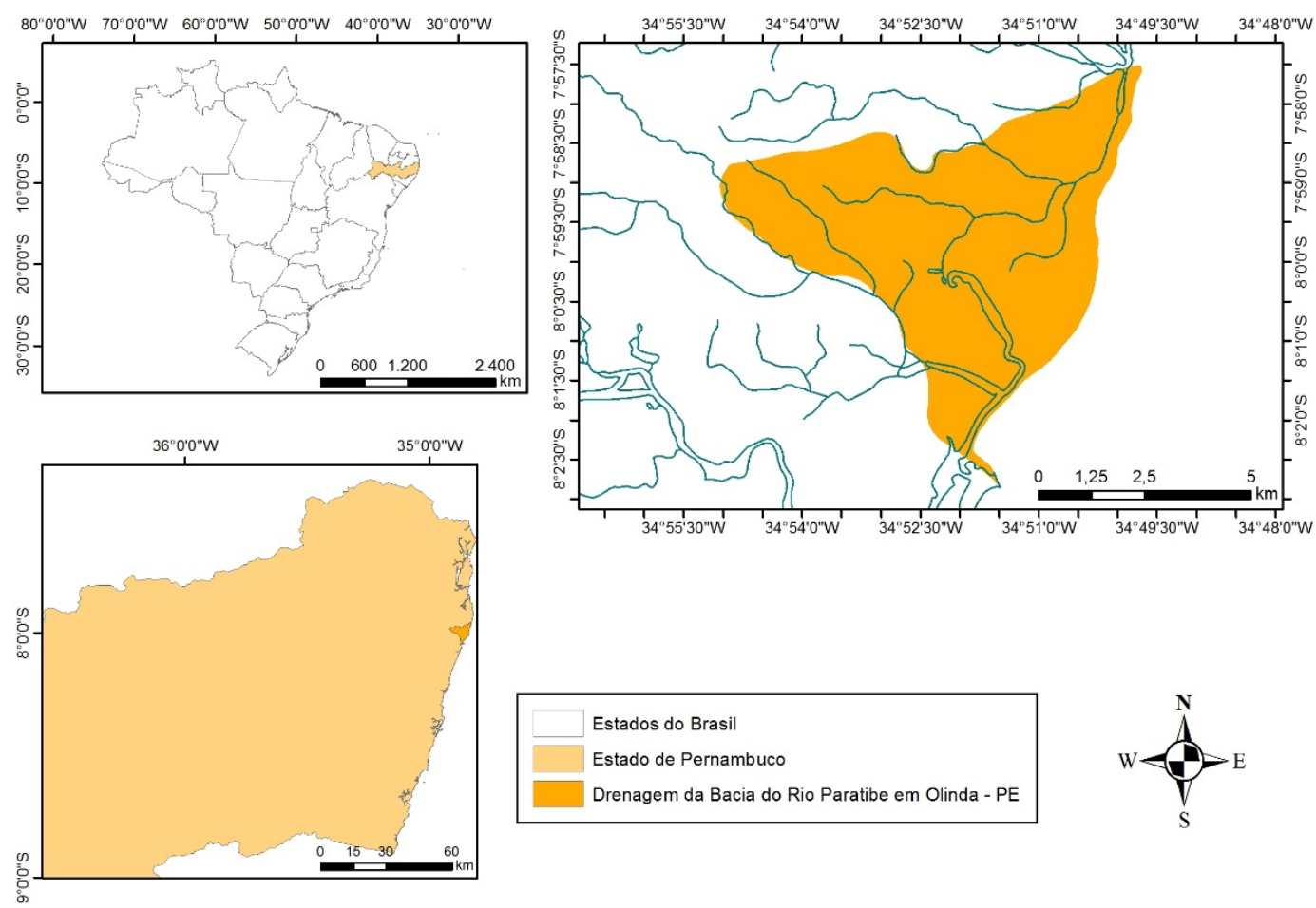

Figura 1: Localização do município de Olinda no estado de Pernambuco e dos cursos fluviais da bacia hidrográfica do rio Paratibe no interior do município.

Fonte: Os autores.

De acordo com Carvalho (2011) a bacia hidrográfica do rio Paratibe está inserida em cinco municípios da região Metropolitana do Recife: Abreu e Lima, Camaragibe, Olinda, Paulista e Recife. No referente ao seu potencial de enchentes e inundações, tais fenômenos ocorrem a partir do seu médio curso, mas são intensificados no seu baixo curso, assim como em seus principais afluentes neste: o canal da Tinta e o rio Fragoso, este último um rio de $2^{\mathrm{a}}$ ordem que tem o riacho Ouro Preto como afluente (Figura 2).

No trecho do riacho Ouro Preto considerado, popularmente conhecido com Canal de Ouro Preto, observou-se em suas margens uma ocupação eminentemente residencial, mas com presença de pequenos comércios e mesmo de uma escola pública. 


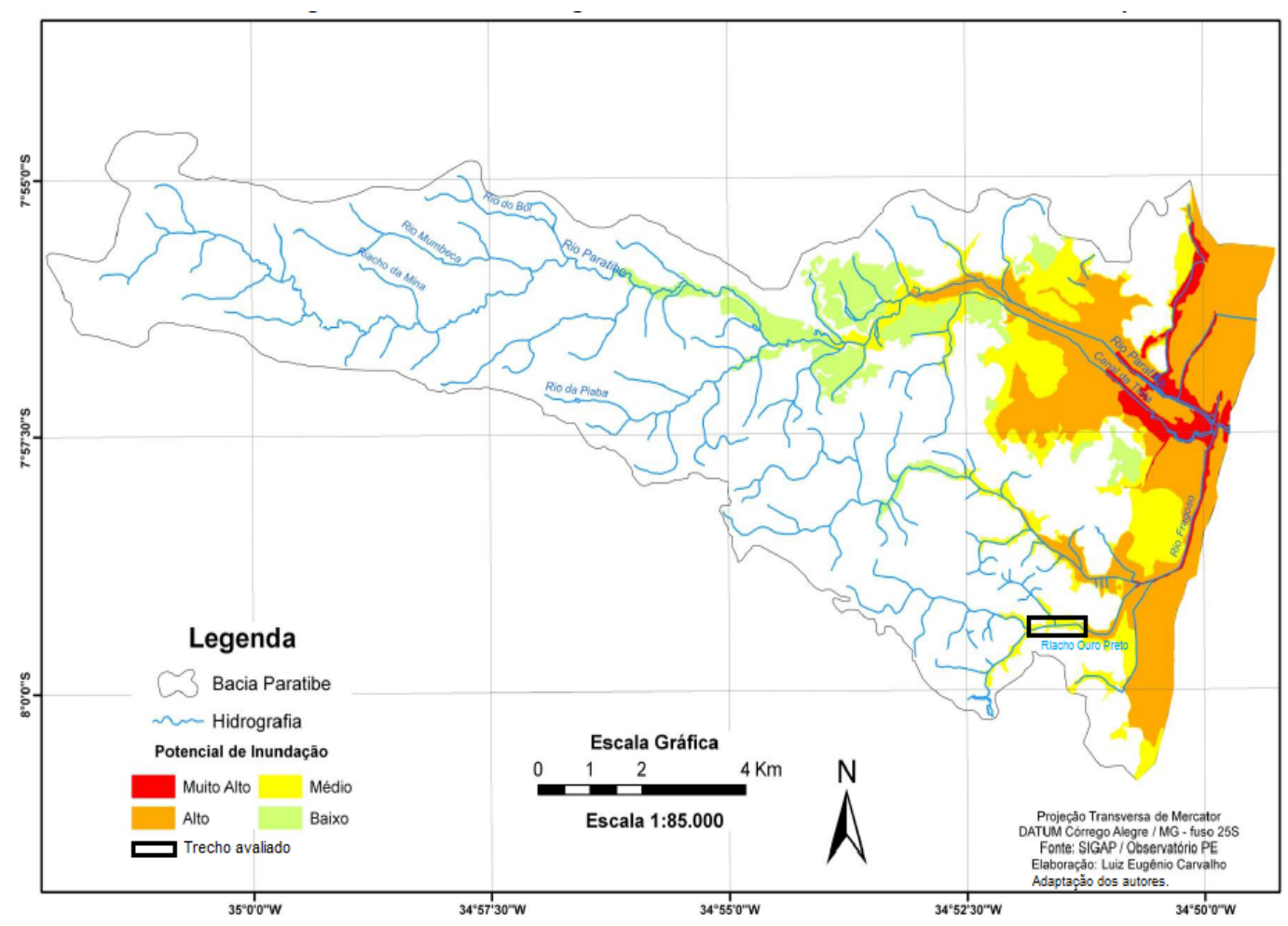

Figura 2: Localização do trecho avaliado na Bacia Hidrográfica do Rio Paratibe - o trecho apresenta média susceptibilidade a inundações.

Fonte: Adaptado de Carvalho (2011).

Considerando as ações de revestimento, retificação e ocupação das margens, estas estão presentes e respondem pela potencialização dos processos de alagamentos e inundações (Figura 3). Ações de revestimento de canal associadas à ocupação do solo, inclusive da planície de inundação, podem ser responsáveis por consequências danosas à dinâmica hidrológica de um canal fluvial, pois os revestimentos modificam as relações hidrodinâmicas entre as vias de interação das zonas ripária e hiporreica do curso d’água e o aumento da velocidade de escoamento, enquanto o processo intensivo e expansivo da urbanização contribui para gradativa diminuição da capacidade de infiltração nas áreas urbanas, provocando alterações significativas nas características do hidrograma de enchente (aumento do fluxo de pico e volumes de escoamento e diminuição do tempo de concentração na bacia) (SANTOS e PINHEIRO, 2002; YANNOPOULOS et al., 2013 e MAUS et al., 2013).

Além das ações impetradas ao domínio fluvial e em suas margens, que tornam o trecho avaliado susceptível à alagamentos e inundações, foram observados outros aspectos que potencializam tais processos, como a presença de densa vegetação em trechos das margens revestidas e mesmo em espaços do revestimento que sofreram colapso, que refletem a não limpeza periódica por parte do poder público municipal de tal ambiente (Figura 4). Também se observou em algumas partes do canal uma grande 
quantidade de resíduos sólidos no interior do canal ou em suas margens, além do lançamento de águas servidas provenientes de áreas residenciais, o que aumento o potencial de extravasamento das águas fluviais.

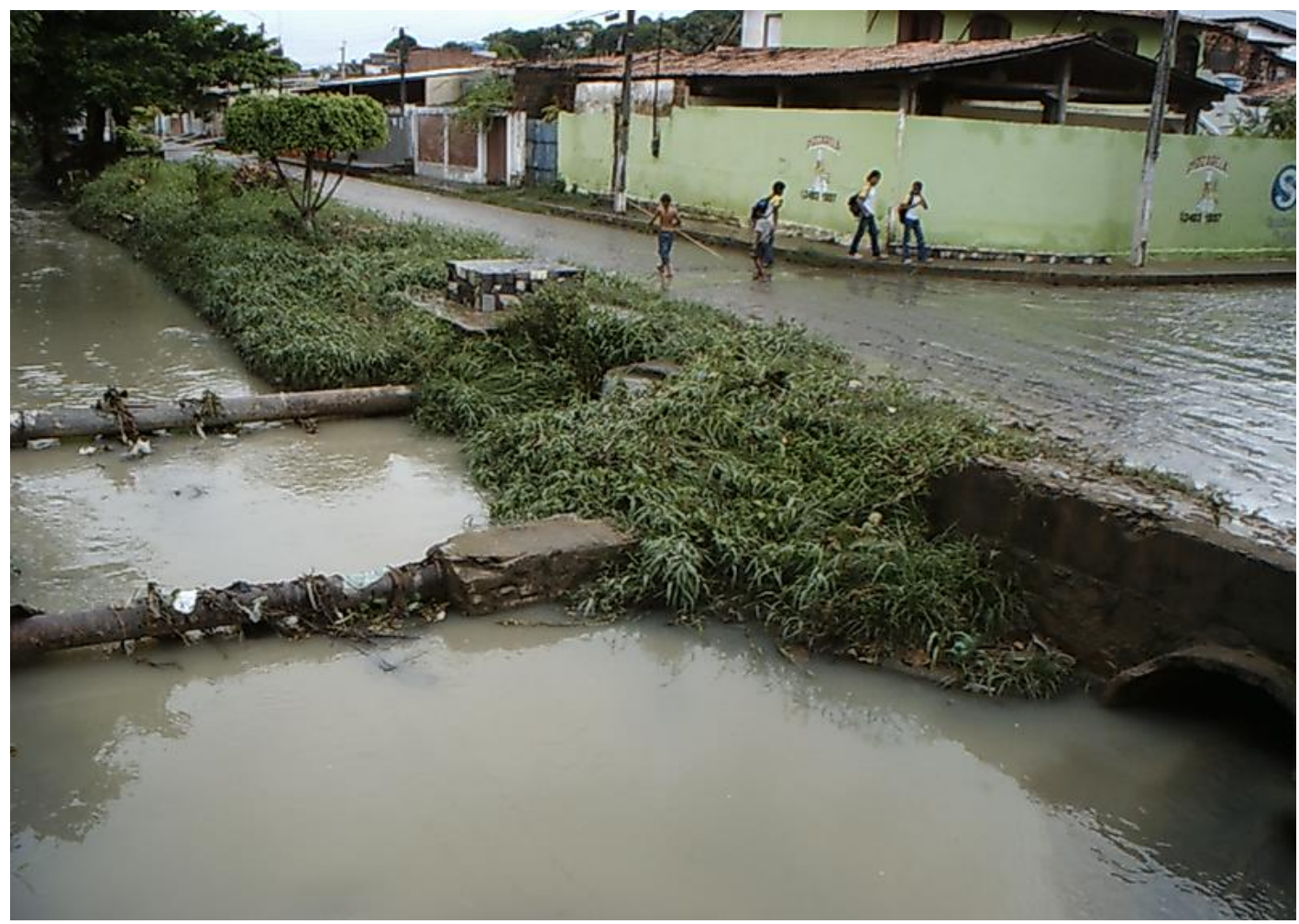

Figura 3: Trecho do canal retificado com estruturas de canalização de água e de despejo de águas servidas. Fonte: Os autores. 


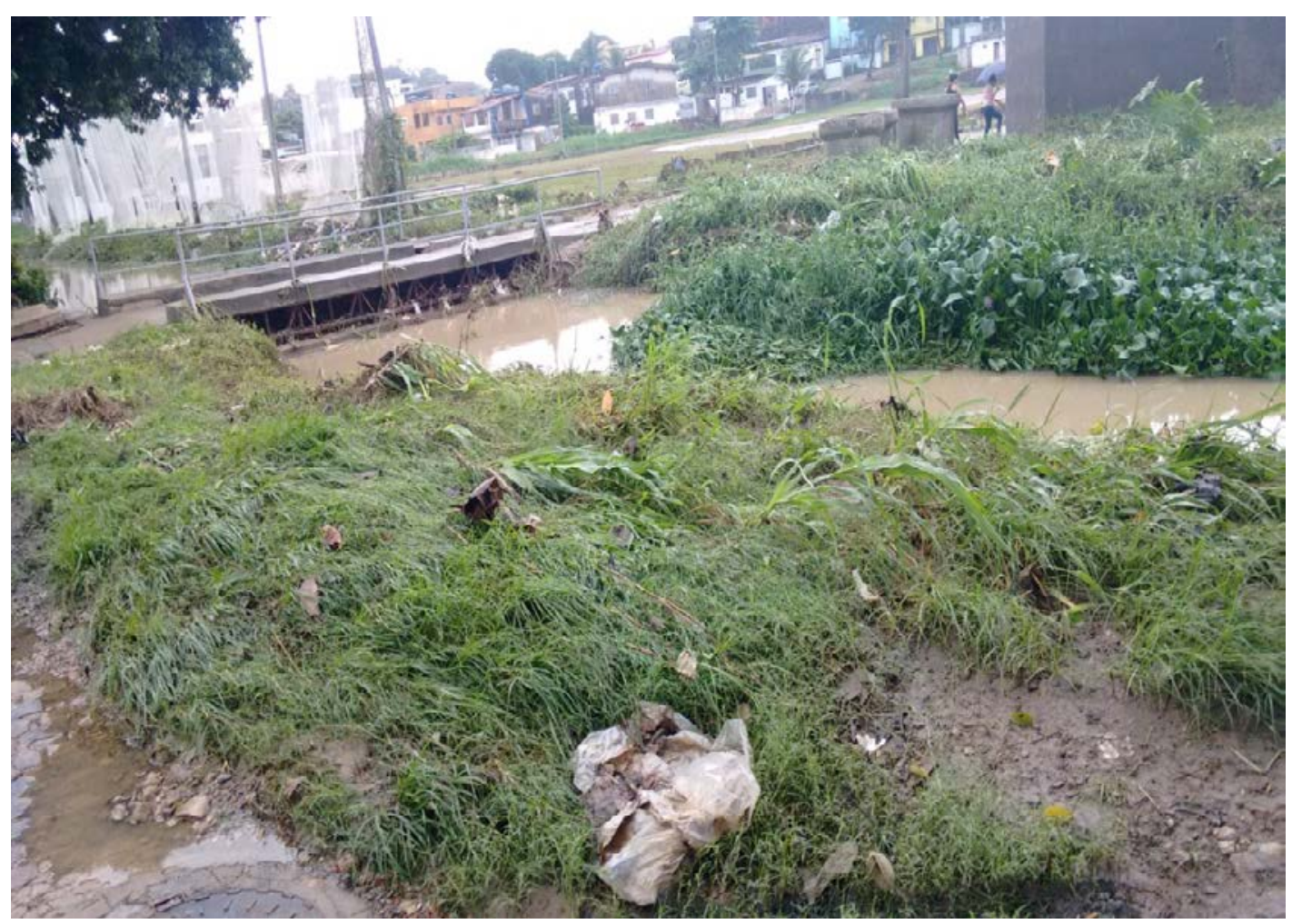

Figura 4: Vegetação ripária densa avançando sobre o canal. Na figura a vegetação encontra-se “abatida” pelo fluxo da corrente relacionada ao aumento do nível das águas quando de um evento pluvial extremo ocorrido em 31/05/2016.

Fonte: Os autores.

O canal do riacho Ouro Preto percorre, aproximadamente 3,5 quilômetros ao longo de áreas urbanas consolidadas ou em processos de urbanização, apresentando um perfil longitudinal que varia entre 12 a 4 metros com inúmeros picos altimétricos que refletem a existência de estruturas antrópicas como canalizações de água encanada, pontes sobre vias e pontes de pedestres (Figura 5).

O trecho do canal apresenta uma configuração retilínea, com perfil longitudinal com pontos de maior profundidade e pontos rasos, evidenciando pontos de acúmulo sedimentar ou mesmo com estruturas antrópicas que promovem modificações do fluxo corrente de águas e sedimentos ao longo do trecho avaliado, contribuindo para potencializar os eventos de enchentes e inundações que, de acordo com a Figura 6, estão mais evidentes no início e final do trecho, levando a barramentos que represam as águas no trecho avaliado durante a ocorrência de chuvas intensas e recorrentes. 


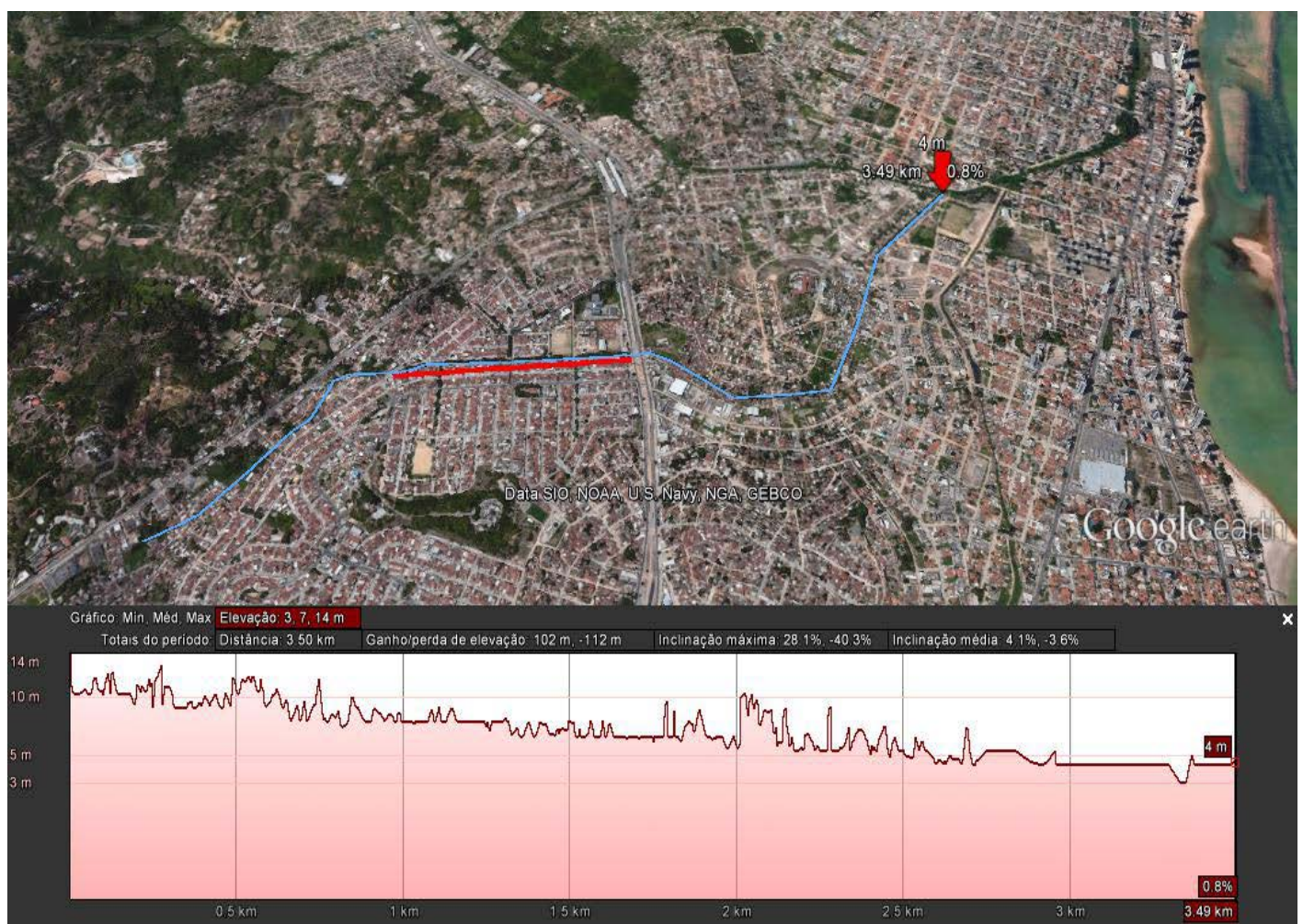

Figura 5: Perfil longitudinal do riacho Ouro Preto apresentando baixo gradiente (12 a 4 metros em 3,5 quilômetros) com pico altimétricos em pontos de estruturas antropogênicas.

Fonte: Os autores

Apesar de durante a maior parte do ano, nas estações de estiagem e de chuvas fracas a moderadas (primavera-verão / setembro a março), o escoamento superficial da bacia está limitado ao canal principal do rio e ser predominantemente unidimensional na direção do curso d’água, tendo o aporte de águas servidas lançadas no canal, no período de chuvas intensas (outono-inverno / março a setembro), ocorrem eventos de alta magnitude e recorrência, principalmente durante os meses de junho e julho, quando o canal tende a transbordar.

Para Tucci (2015) para resolver este tipo de problema, o poder público investe somas consideráveis de recursos em obras de canalização/revestimento de cursos d’água, que na realidade tendem a agravar o problema pela amplificação para jusante das vazões máximas. A magnitude e as consequentes inundações provocadas pelas atuais ocorrências dos eventos hidrológicos em meios urbanos explicitam, não somente, o despreparo social para enfrentar tais ocorrências, mas também a falta de comprometimento com o correto processo de ordenação urbana e territorial sob o ponto de vista de gestão e gerenciamento do crescimento desses espaços (LIMA e RIGHETTO, 2011). 


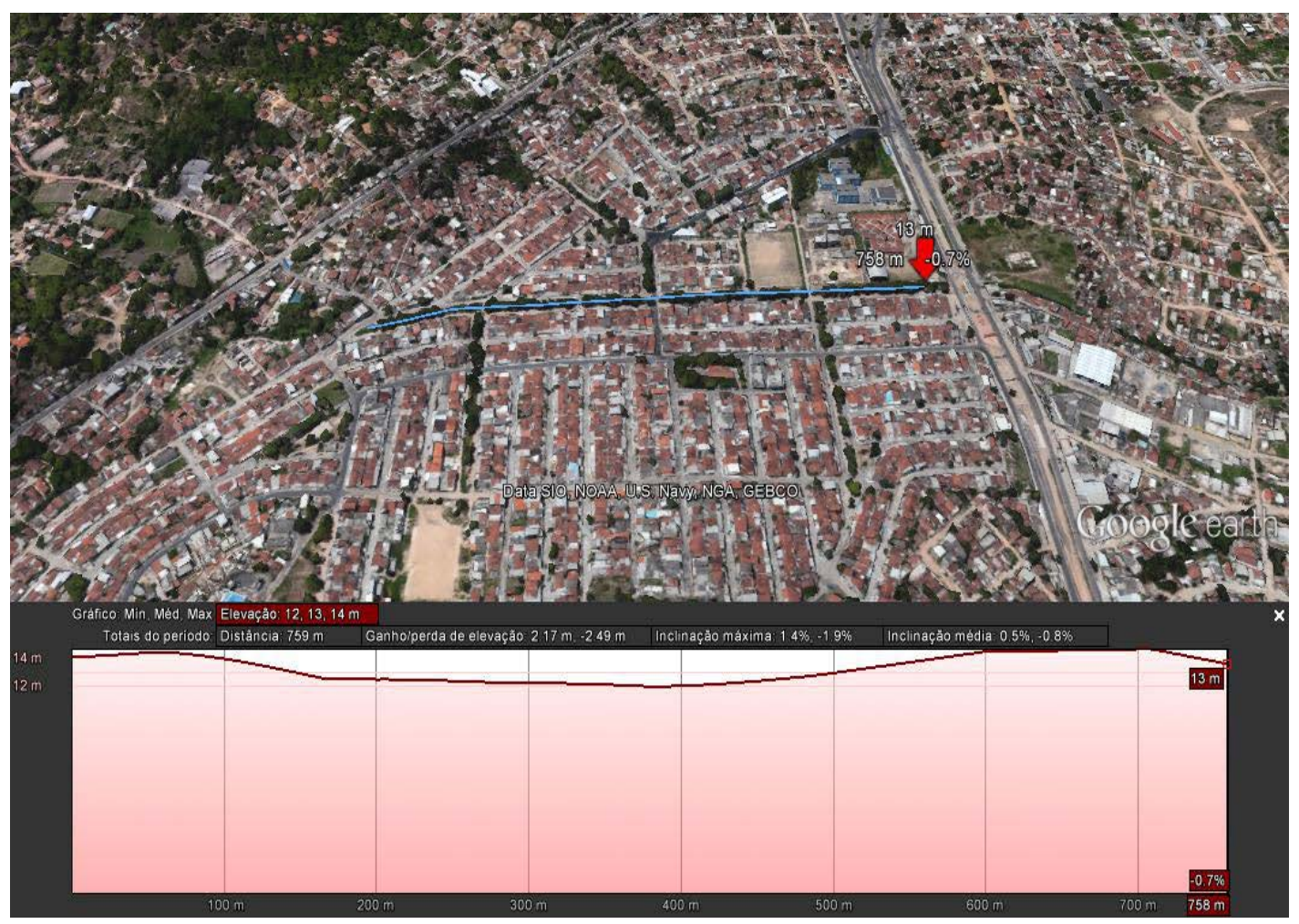

Figura 6: Perfil longitudinal do trecho analisado, apresentando sobressaltos no início e final do trecho em decorrência de estruturas antropogênicas que comprometem a fluidez do canal.

Fonte: Os autores.

\section{CONSIDERAÇÕES FINAIS}

O propósito deste trabalho foi realizar uma análise inicial das formas de ocupação do riacho de Ouro Preto e como estas influenciam para potencializar ocorrências de eventos de alagamentos e inundações. Constatou-se que a área marginal do canal, ou a planície aluvial, está ocupada por edificações que comprometem as interações processuais hidrológicas, geomorfológicas e também biológicas do sistema interflúvio-fundo do vale.

Tal constatação reflete uma situação corrente nas cidades brasileiras que apresentam os cursos d'água frequentemente desconsiderado suas funcionalidades como elementos estruturadores do ordenamento ambiental e territorial, sendo, por muitas vezes, tratados como problemas em decorrência dos recorrentes eventos hidrogeomorfológicos que atingem áreas ocupadas. Fato inconteste é que deveriam ser resguardadas, fazendo com que estes não sofram com ações voltadas para seus revestimentos marginais e retificações que só potencializam eventos danosos a populações que residem em suas proximidades.

Ações de revestimento e retificação de canais aumentam a velocidade de fluidez da água corrente, mas levam a modificações na calha do rio e, consequentemente, causam impactos ao canal e planície de 
inundação, sendo comum o desencadeamento de mudanças no padrão de drenagem, reduzindo o comprimento do canal pós alargamento, aprofundamento e retificação, e ainda promovendo a diminuição de rugosidades do leito e aumento do gradiente.

Já no domínio interfluvial a impermeabilização das margens e interflúvios reduz ou inviabiliza espaços naturais ao escoamento de vazão nas margens e planície aluvial, minimiza o processo de infiltração das águas pluviais, com o consequente aumento e aceleração do escoamento superficial e, por conseguinte, aumento da vazão e os picos destas, principalmente a jusante de trechos retificados e impermeabilizados, aspectos constatados ao longo do trecho considerado e que levam a potencializar eventos recorrentes na localidade, principalmente durante o período chuvoso.

\section{REFERÊNCIAS}

CARVALHO, Luiz Eugênio Pereira. Os descaminhos das águas na metrópole: A socionatureza dos rios urbanos. 2011. 176 f. Dissertação (Mestrado em Geografia) - Departamento de Ciências Geográfica, Universidade Federal de Pernambuco, Recife. 2011.

MAUS, V. W.; RIGHES, A. A. \& BURIOL, G. A. Pavimentos permeáveis e escoamento superficial da água em áreas urbanas. In: I SIMPÓSIO DE RECURSOS HÍDRICOS DO NORTE E CENTROOESTE, 1, 2007, Cuiabá. Porto Alegre: Associação Brasileira de Recursos Hídricos, 2007, 8p.

LIMA, R. R. M. de; RIGHETTO, A. M. Modelagem hidrológica em bacias urbanas com nível de discretização de lotes e quadras. In: XIX SIMPÓSIO BRASILEIRO DE RECURSOS HÍDRICOS, 19, 2011, Maceió. Porto Alegre: Associação Brasileira de Recursos Hídricos, 2011. 14p.

SANTOS, G. F. dos; PINHEIRO, A. Transformações geomorfológicas e fluviais decorrentes da canalização do rio Itajaí-Açu na divisa dos municípios de Blumenau e Gaspar (SC). In: Revista Brasileira de Geomorfologia, Ano 3, n. 1. p. 1-9, 2002.

TUCCI, C. E. M. Elementos para o controle da drenagem urbana, 2015. p.1-10.

YANNOPOULOS, S. I.; GRIVAKI, G.; GIANNOPOULOU, Io.; BASBAS, S.; OIKONOMOU, E. K. Environmental impacts and best management of urban stormwater runoff: measures and legislative framework. Global NEST Journal, v. 20, n. 10, p. 1 - 9, 2013.

Recebido em: 14/08/2016

Aceito para publicação em: 01/10/2016 